\title{
The Effects of Electricity Costs on Firm Re-location Decisions: Insights for the Pollution Havens Hypothesis?
}

\author{
Matthew Panhans ${ }^{1}$ - Lucia Lavric ${ }^{2}$. Nick Hanley ${ }^{3}$
}

Accepted: 13 July 2016 / Published online: 1 August 2016

(C) The Author(s) 2016. This article is published with open access at Springerlink.com

\begin{abstract}
Electricity costs are partly driven by environmental policy choices. In this paper, the effects of variations in electricity costs-as measured by end-user electricity prices-on firm relocation decisions are investigated. Using a discrete choice model and a data base that has not previously been exploited to study this problem, we investigate the effects of variations in electricity costs on the intensive and extensive re-location decisions of European firms. We find that electricity costs play a significant role in determining relocation destinations. This effect is asymmetric between firms moving into and out of a country, and between high and low energy intensity sectors. The findings of the paper have implications for the Pollution Havens Hypothesis, since they show the extent to which the effects of climate policy on domestic electricity costs can be expected to impact on firm relocation decisions both into and out of a country.
\end{abstract}

Keywords Firm re-location · Energy costs · Pollution Havens Hypothesis · Climate policy · Carbon leakage

JEL Classification D22 $\cdot \mathrm{F} 18 \cdot \mathrm{Q} 41 \cdot \mathrm{Q} 52$

\footnotetext{
$凶 \quad$ Nick Hanley

ndh3@st-andrews.ac.uk

Matthew Panhans

matthew.panhans@duke.edu

Lucia Lavric

lucia@encompassecon.com

1 Department of Economics, Duke University, Durham, NC, USA

2 Encompass Economics, Edinburgh, Scotland

3 Department of Geography and Sustainable Development, University of St Andrews, St Andrews, Scotland
} 


\section{Introduction}

For many years, academics and governments have been interested in the effects of environmental policy on the location decisions of firms (Ulph 2000). One focus for this interest has been the Pollution Havens Hypothesis (PHH). This hypothesis is concerned with the effects of changes in the severity of pollution regulation on plant location decisions and trade flows (Eskeland and Harrison 2003; Copeland and Taylor 2004). It remains an open empirical question whether pollution control costs are important enough to measurably influence trade and investment, both because the PHH operates on different levels in different contexts, and because of limitations of data that have restricted the modeling of a firm's location decision. Yet this is a very important question, particularly for climate change policy. Policymakers concerned with addressing climate change might consider regulations that make it more costly for firms to emit greenhouse gases, so as to reduce total emissions. However, if the PHH is a valid concern, climate change regulations might cause firms to relocate their activity to another country with less stringent regulations ("carbon leakage": Fischer and Fox 2012; Elliot and Fullerton 2014), whilst reducing economic activity in the initial host country. As greenhouse gases are a global pollutant, carbon leakage reduces the effectiveness of domestic climate policy.

This paper takes advantage of a unique dataset of EU firm relocations in order to add to the empirical evidence on the potential economic impact of climate policies, by considering the relationship between industrial electricity prices at the country level and the location decisions made by internationally-mobile firms. Thus we see this investigation as a contribution to the PHH literature and to on-going policy discussions about carbon leakage risks. The data, described below, lends itself to modeling firm location decisions in a discrete choice framework where firms choose where to locate among a choice set of potential destination countries. This modelling framework is based on the approach originally developed in McFadden (1974). In order to model firm behavior in this way, we use country-level characteristics to serve as the choice attributes; these are described in the data section below. We then explore the effects of potential future changes to environmental regulation by examining the response of firms to changes in a country's electricity prices, as these often embody a large proportion of climate mitigation policy costs. The added costs of climate policies have impacts on different parts of the electricity supply system, ranging from generation to transmission. The magnitude of these added costs resulting from climate policies such as carbon taxes, cap-and-trade schemes and mandatory renewable energy targets varies across countries, partly according to the commercial and regulatory structure of their electricity systems, and it is difficult to separate the effects of such climate policies from other electricity price drivers such as domestic regulatory regimes, competition, electricity import and export options and historic investments in alternative electricity generation sources. Despite these limitations, we believe that final electricity prices to industrial consumers are a reasonable proxy for the added costs of climate mitigation policy. If firms react in a similar way to increased pollution costs as they would to an increase in electricity prices, then variations in electricity prices can be used as a proxy for variations in climate policy stringency.

Two models are investigated. The first is conditioned on firms having already decided to re-locate, so that the choice to be explained is where they will decide to move to. The second expands the choice process to include the decision as to whether to re-locate or stay, as well as where to move. We are particularly interested in whether there is a symmetric effect of higher electricity costs on firms thinking about moving out of a country compared to firms thinking about moving in; since any asymmetry would be important from a policy viewpoint. 
We are also interested in comparing the elasticity of firm response to an increase in electricity costs between high- and low-energy intensity sectors, since a priori one would expect highly energy-intensive sectors to be more sensitive to variations in electricity prices.

After reviewing the previous literature in the next section, we discuss our data in Sect. 3. Section 4 discusses the conditional relocation model and results, and Sect. 5 presents the unconditional relocation model. Section 6 investigates firm heterogeneity, and Sect. 7 concludes. The main results of the empirical analysis are that electricity costs do play a significant role in determining relocation destinations, but also that effect is asymmetric between firms moving into and out of a country, and between high and low energy intensity sectors.

\section{Environmental Policy, Energy Costs and Firm Location: An Overview of the Literature}

Historically, the theoretical and empirical literatures on firm competiveness and location decisions of plants contains two distinct strands: one related to the costs associated with environmental regulation (the pollution haven hypothesis), and another related to the impact of energy costs on the location of firms as part of factor proportion models where trade flows are determined by relative factor endowments. In this context, energy prices were used in the literature as a proxy for endowment with energy resources.

\subsection{General Overview of PHH Literature}

According to Eskeland and Harrison (2003), "the pollution haven hypothesis is, perhaps, best seen as a corollary to the theory of comparative advantage: as pollution control costs begin to matter for some industries in some countries, other countries should gain comparative advantage in those industries, if pollution control costs are lower there (for whatever reason)." Baumol and Oates (1988), Pearson (1987), Wilson (1996), Ulph (1997), Rauscher (1994, 1997, 2000), List and Mason (2001), Verbeke and Clerq (2002), and Conrad (2005) develop different theoretical models that illustrate the problem.

Empirical testing of the PHH has not yielded conclusive results, partly because of some of the empirical difficulties facing the analyst. These include developing appropriate measures of regulatory stringency, dealing with unobserved heterogeneity at the country or state level, and possible simultaneity concerns between FDI (or some other measure of economic performance) and regulatory stringency (Brunnermeier and Levinson 2004). Copeland and Taylor (2004) undertake a review of the pre-2002 literature and conclude that most early studies found little evidence of the pollution haven effect using cross-section estimation techniques, due in part to the econometric issues noted above, but that studies which use more robust estimation and panel data were more likely to find a significant PHH effect. Brunnermeier and Levinson (2004) also concluded that "studies that...control for unobserved heterogeneity, or ...control for endogeneity find statistically significant pollution haven effects of reasonable magnitude." (page 6) Other studies such as Jeppesen et al. (2002) and Ben Kheder and Zugravu (2008) also find a negative relationship between the stringency of environmental regulation and plant location decisions. In contrast, Eskeland and Harrison (2003) find that the empirical relationship between location and abatement expenditures is "not..robust", whilst Millimet and List (2004) found heterogeneous effects of environmental regulatory burdens on plant start-up and exits for US county-level data.

The PHH literature has followed developments in international trade theory, with factor endowment aspects commonly controlled for in earlier studies. Agglomeration metrics have 
been added in later studies such as Wagner and Timmins (2009). Firm re-location in response to variations in the costs of meeting environmental regulations can also be linked to the effects of variations in regulatory burden on Foreign Direct Investment flows between countries (Cole and Elliott 2005; Buch et al. 2005). Both Wagner and Timmins (2009) and Cole and Elliott (2005) show variation in responsiveness to environmental regulation by sector. The former shows the sensitivity of the chemicals sector (relative to metals and pulp and paper sectors) in terms of the relationship between location decisions and environmental burdens, whereas the latter underlines differentiated results by capital intensity.

\subsection{Energy Costs and Location Decisions}

Ratti et al. (2011) use individual firm data from 15 European countries across 25 industries over the period 1991-2006 to show a negative effect of energy prices on investment, with manufacturing sectors particularly sensitive to these effects. Ben Kheder and Zugravu (2008) use electricity price data in a study of location decisions made by French firms between 1996 and 2002. Their conditional logit specification includes market potential variables such as GDP, population size and distance from other important markets, as well as labour and capital costs. Other variables include an Environmental Regulation Index built on the basis of information of international environmental agreements ratified, the energy efficiency of output and general investment friendliness indices such as corruption and the rule of law. Findings suggest that investment decisions are negatively related to fuel prices.

A forecasting exercise based on empirical evidence by Broeren et al. (2014) focuses on the location of chemical plants on basis of the costs of production. Energy prices, especially natural gas and other primary energy, constitute one of the main drivers for plant location along with the cost of transport and technology requirements. In the case of chlorine production, the cost of electricity is particularly important. The study concludes that by 2030 as much as $60 \%$ of basic chemicals production will be located in non-OECD countries, due to lower energy costs. In the context of non-industrialised countries, where higher energy consumption is associated with energy subsidies, the impact of energy prices on FDI has indirectly been tested as part of the extensive literature dealing with the interaction of energy consumption, FDI and economic growth. Lavric (2013) produced a study that focused on the countries from where industry relocates and on the existing evidence of the impact of electricity charges on relocations from the EU manufacturing sectors using the ERM database. She shows significant effects of a number of factors evoked in the wider trade literature, but does not find evidence that higher electricity charges are linked to a higher incidence of relocation events in any sectors other than possibly the food sector.

A number of studies have recently been undertaken to determine the effect of increased electricity prices on industrial competitiveness in the European Union. These studies ${ }^{1}$ have been undertaken both as part of the discussion on EU Emissions Trading Scheme allowance auctioning, as well as in relation to the impacts of setting renewable energy targets. Individual Member States such as Germany and the UK, where the cost of emissions reductions is generally included in the cost of electricity supply, have also commissioned studies to determine the competitiveness impacts of increased electricity prices on domestic manufacturing. ${ }^{2}$ Martin et al. (2014) produced a novel exercise of assessing the risk of carbon leakage from European EU ETS firms by using a new approach to surveying industry aimed at reducing response biases. The authors find that the currently applied EU ETS method of preventing

1 For example, Öko-Institute.V. and Ecofys (2013).

2 For example, ICF (2012) and Frontier Economics and EWI (2010). 
carbon leakage amounts to considerable over-compensation. Commins et al. (2011) use of cross-country firm level panel data, for a large sample of European companies. They assess the effect of energy taxes and the introduction of the EU Emissions Trading Scheme on employment, investment and productivity between 1996 and 2007. The authors find that both the magnitude and sign of results dramatically between sectors; total factor productivity accelerates with higher carbon taxes in some sectors and decelerates in others; energy taxes lead to a net reduction in employment reduce employment and to increased investments as well as a shift in investment patterns across sectors.

In conclusion, a number of literatures have investigated the theoretical and empirical links between environmental policy, energy costs and firm location choices. However, there are few clear messages that emerge from this body of work. Research which provides additional insight into these linkages would thus seem worthwhile. In what follows, we first describe the data used in our study, before setting out the modelling approach and results. The main research questions investigated are these: at the firm level, can we observe an effect of variations in electricity prices on firms' decisions whether to stay or move? Is this effect symmetrical for those moving into versus out of a country? And how does the responsiveness of firms to energy costs vary with the energy intensity of the sector within which they operate?

\section{Data}

The present study makes use of EU-wide data to study the responsiveness of large manufacturing firms to changes in electricity prices across countries. Our primary data comes from Eurofound's European Restructuring Monitor (ERM), which conducts a comprehensive screening of press and online news sources in the European Union (EU) to collect data on firm restructuring. An "event" is included in the dataset if it involves the destruction or creation of at least 100 jobs, or at least $10 \%$ of the workforce at sites employing more than 250 people. We focus on events from the ERM that involve the relocation of manufacturing activity from within the EU to another country, either within or outside of the EU. We model this relocation decision in a discrete choice framework, with the choice set defined as the set of possible destination countries to which a firm can relocate. In this way we investigate which factors drive the firms' relocation decisions, focusing on their responsiveness to costs of energy inputs, since this may give an indication of how firms will respond to environmental regulations that drive up their energy costs.

The industrial sectors included in the dataset are given in Table 1, and descriptive statistics of the size of the relocations are given in Table 2. We drop observations which do not tell us the specific destination country. We also treat as independent events any firm relocation that

Table 1 Sample of sectors observed
Number of firms

\begin{tabular}{lr}
\hline Manufacture of computer and electronics & 90 \\
Manufacture of electrical equipment & 113 \\
Manufacture of motor vehicles & 102 \\
Manufacture of food products & 37 \\
Manufacture of chemicals & 31 \\
Manufacture of rubber and plastics & 31 \\
Manufacture of fabricated metal products & 22
\end{tabular}


Table 2 Summary statistics

\begin{tabular}{|c|c|c|c|c|c|}
\hline & Obs & Mean & SD & Min & Max \\
\hline \multicolumn{6}{|l|}{ Size of relocation events } \\
\hline Jobs affected & 634 & 294.3 & 323.9 & 30 & 3200 \\
\hline \multicolumn{6}{|c|}{2012 destination country characteristics } \\
\hline GDP (billions \$) & 57 & 1102 & 2506 & 7.253 & 16,245 \\
\hline Tax rate (\% of commercial profits) & 57 & 42.74 & 16.68 & 7.4 & 107.5 \\
\hline GDP per capita (\$) & 57 & 26,076 & 24,520 & 1503 & 106,023 \\
\hline EU member & 57 & .42 & .498 & 0 & 1 \\
\hline Price of electricity (cents/kWh) & 57 & 0.122 & .0599 & .022 & .292 \\
\hline
\end{tabular}

The GDP, GDP per capita, and tax rate data come from the World Bank's "World Development Indicators" catalogue. The tax rate used is from the data series "Total tax rate (\% of commercial profits)" which measures the amount of taxes and mandatory contributions payable by businesses after accounting for allowable deductions and exemptions as a share of commercial profits. It has a max above $100 \%$ because in 2012, Argentina had a reported total tax rate above $100 \%$

involved shifting manufacturing production to multiple destination countries. After cleaning this data, we are left with 634 observations of relocations over the period 2002-2013. For each relocation, we observe the firm name, year of relocation, country of origin, country of destination, industry sector, and the number of jobs affected. The relocation events are shown graphically in Fig. 1 by origin-destination pairs.

There are some limitations to this relocation dataset. Given the criteria for inclusion in the dataset, there is a firm size bias as the dataset will include almost exclusively medium to large sized firms. In addition, variability in national coverage of restructuring events would lead to an uneven representation across the EU. Despite these limitations, this data is unique as an EU-wide dataset of large-scale restructuring and relocation events. Other data that are crucial for our investigation are energy prices. We compiled a consistent time series of end-user electricity prices for industry from several sources. Most of the data on electricity prices come from the International Energy Agency (IEA). The IEA provides data for OECD countries and select non-OECD countries, but does not include all countries that are relevant to our study. For these countries we obtain electricity prices from Enerdata. For the few countries that do not have end-use electricity prices for industry available in either of these sources, we obtained prices from either the national power company of that country or a published research article on the electricity market of the relevant country. ${ }^{3}$ Note that the prices of other fuels used by industry (such as fuel oil and natural gas) are not included in the dataset, due to gaps in data coverage for several countries to which relocations are important. We discuss the implications of omitting these substitute prices below and in the Conclusions.

3 Indeed for some of the non-OECD countries, the price of electricity time series is quite incomplete, with a few countries having only 1 data point. We use linear interpolation and extrapolation to complete the dataset, that is we fill in missing years that have prior and future observations by fitting a linear trend, while missing values at the beginning or end of the sample are fit to a linear trend of the two closest observations. Alternatively, we also calculated the annual average percent change in electricity prices from the observed data, and used this to impute the missing values for particular countries, assuming that energy prices in a country might follow global trends to some degree. The results were almost exactly identical for both methods, suggesting that the imputation of missing values does not drive our results. As a final robustness check, we perform the analysis only using countries for which we have very completely series of prices over the sample period. These results are presented in Table 5, and again show similar results. 


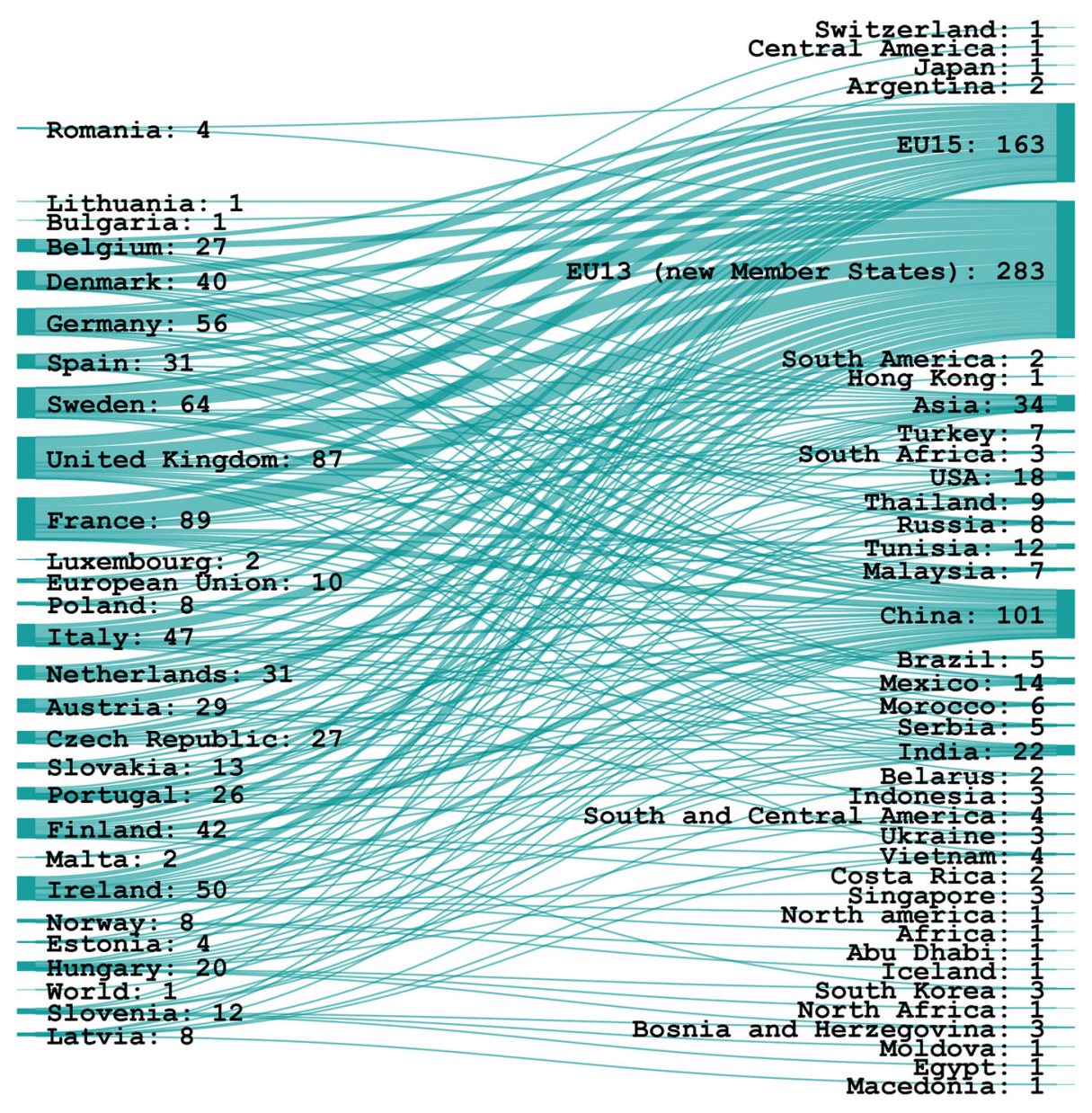

Fig. 1 Relocation flows from the EU, as recorded by the European Relocation Monitor for January 2002 to June 2013

Our discrete choice framework requires other country-level attributes, which will serve to control for country characteristics that might influences a firm's relocation decision. We obtain bilateral trade data from the Eurostat COMEXT database. This is to capture the idea that for a domestic firm that is relocating, the choice among two alternative countries may be influenced by the amount of trade between the domestic country and each of the potential destinations. A high value of exports of a product category (in our case a NACE 2 category) to a country can indicate an attractive market for the exported product. A high value of imports may serve as an indication of the exporter's competitive advantage, caused by lower factor costs and agglomeration effects. The World Bank provides other country-level attributes for most of our destination countries, including a complete time series of GDP for the countries in our study. GDP, as a measure of market size, is commonly used in empirical studies based on gravity international trade model and is also used in the PHH literature, e.g. Smarzynska and Wei (2001). This is typically used in conjunction with measures of distance and "virtual" distance such as differences in language (e.g. Head and Mayer 2004). Both distances between countries and language differences are included in our modelling as part 
of the costs of moving. Labour costs are a variable commonly used in empirical PHH and wider trade literature, e.g. Millimet and List (2004) and Buch et al. (2005). Unfortunately, no consistent and comprehensive time series on country-specific labour costs could be found, so that cross-country variations in labour costs are only included via the time-unvarying country fixed effects. Finally, the World Bank collects time series data on the total tax rate for businesses in each country, measured as a percentage of total commercial profits.

Other sources provide many of the country-specific attributes we use in the choice model. The CIA World Factbook provides data on tax rates and unemployment rates for each country. Head and Mayer (2004) find that corporate taxation carries a negative, large coefficient in their study of location decisions of Japanese car manufacturers in Europe. The Quality of Government Institute has compiled a dataset that for each country measures indices of quality of government institutions, perceived corruption, levels of infrastructure and quality of education. These variables are commonly used in the trade literature and are included as proxies for the cost of trade. The quality of infrastructure emerges as a significant variable in the review of the PHH literature by Brunnermeier and Levinson (2004); this is also used in Wagner and Timmins (2009) and others.

\section{Modelling Approach: Relocation Choice}

Discrete choice models are used to describe decision makers' choices between alternatives (Ben-Akiva and Lerman 1985). The decision makers can be individuals, households, firms, or government agencies, but in order to fit into the discrete choice framework the decision maker must face a finite, exhaustive, and mutually exclusive set of choices where only one alternative is chosen on each choice occasion. The firm relocation data from the European Restructuring Monitor includes the destination choice of individual manufacturing plants, making it particularly well suited to a discrete choice framework, with firms choosing a relocation destination from among the set of countries.

Earlier work has also used the discrete choice framework to study firm location decisions. Manderson and Kneller (2012) use a probit model to study firms' FDI response to environmental regulation. As a robustness check, those authors use a multinomial logit model with a choice set of the world divided into 10 regions (e.g. North America, Western Europe, etc.). We use a multinomial logit model with countries as the choice set, and also account for the varying moving costs between each pair of countries. Levinson (1996) uses data from the Census of Manufacturers to estimate a conditional logit of plant relocations across U.S. states in response to state-level characteristics including environmental regulations. Levinson finds that the locations of branch plants of large firms are more sensitive to state characteristics than plants in general; however, only a few of the coefficients on measures of environmental stringency are statistically significant. Another early paper of firm entry in an oligopolistic market is Bresnahan and Reiss (1991), which touched off the literature on firm entry games. Although we see the relocation decisions of manufacturing firms in the data set used here, they are all in different markets, and thus we do not model them as strategically interacting and so do not build an entry game. We adopt an estimation strategy based on a model where firms choose a country based on its characteristics, and taking moving costs into account. We can then estimate the value of country-specific characteristics, such as the end-user price of electricity in each country, to evaluate how important that is to each firm's location decision. ${ }^{4}$

4 Some papers have extended these models to dynamic settings, for example Bayer et al. (2011) who present a dynamic model of a household's neighborhood location choice. However, because we do not observe the same firm making multiple moves in the ERM relocation data, we maintain a static framework in this paper. 


\subsection{Empirical Model}

We model firm i's decision to relocate a plant conditional on the firm deciding that it will relocate to another country in a particular year. We provide a richer model that includes the decision of whether to relocate or not in the next section. The firm chooses a country $\mathrm{j}=1,2, \ldots, J$ for each year $\mathrm{t}=1, \ldots, T(2002-2013)$. Because this choice is conditional on relocation, each firm faces $\mathrm{J}-1$ alternatives, as we exclude the country of origin from the choice set. Thus at each time period, each firm $\mathrm{i}=1, \ldots, N$ faces a reduced form profit function:

$$
\pi_{i j t}=\delta_{j}+\beta_{1} \text { Price_elec }_{j t}+\beta_{2} G D P_{j t}+\beta_{3} \text { Trade }_{i j t}+\beta_{4} \text { Tax }_{j t}+\epsilon_{i j t}
$$

with a moving cost function

$$
\theta^{\prime} M C_{i j}=\theta_{1} \text { Dist }_{i j}+\theta_{2} \text { Lang }_{i j}+\theta_{3} E U_{j t}
$$

and where the mean profit term, $\delta_{j}$, serves as a country-specific fixed effect. In our specification we define the following:

- Price_elec $c_{j t}$ are the end-user electricity costs for industry in country $\mathrm{j}$ at year $\mathrm{t}$

- $G D P_{j t}$ is the gross domestic product of country $\mathrm{j}$ in year $\mathrm{t}$

- Trade $_{i j t}$ is a measure of bilateral trade between countries $\mathrm{i}$ and $\mathrm{j}$ in year $\mathrm{t}$

- $\operatorname{Tax}_{j t}$ is the total tax rate, measured as the amount of taxes and mandatory contributions payable by businesses as a share of commercial profits in country $\mathrm{j}$ in year $\mathrm{t}$

- $X_{j}$ are country specific attributes that do not vary with time

- Dist $t_{i j}$ is distance, measured as kilometers between countries $\mathrm{i}$ and $\mathrm{j}$

- Lang $_{i j}$ is a dummy variable equal to 1 if firm i's country of origin has an official language in common with $\mathrm{j}$

- $E U_{j t}$ is a dummy variable for EU membership at time $\mathrm{t}$

$\epsilon_{i j t}$ is an i.i.d. Type I Extreme Value distributed shock. This is so that the choice probabilities can be expressed in a closed form, which greatly facilitates estimation. The EU membership indicator is included because there may be a different cost of relocating within the EU compared to outside the EU, possibly due to differences in legal or regulatory regimes. The per capital GDP is included to capture some indication of effective market demand. In some specifications, we also include GDP per capita to approximate labor costs, but as it tends to be correlated with total GDP for each country-year, it does not add much additional variation and results remain similar.

\subsection{Estimation}

The destination-specific constant $\delta_{j}$ captures time-invariant omitted variables, which may be correlated with the error term. Thus, by adding this constant, we control for endogeneity that might arise from time-invariant omitted variables. In estimation of the logit model, we recover the coefficients on Price of Electricity, GDP, Trade, Taxes, and Moving Costs $\left(\beta, \theta^{\prime}\right)$ and the mean profit terms, $\left\{\delta_{j}\right\}$. The coefficient on moving costs is identified from variation in the distances that firms from different origin counties would need to travel to relocate to the various destination countries, while the other remaining parameters are identified by time variation in their values.

The estimation is done via Maximum Likelihood Estimation (MLE), on the likelihood function generated by the multinomial logit model with alternative-specific constants. The primary subtlety in our context comes from that fact that after deciding to relocate, each firm 
faces a choice set of all countries, excluding the country of origin; thus, firms originating in different countries will face different choice sets. In specifications where we allow firms to decide to remain in the country of origin, this manifests itself as the firms facing zero "moving costs" when choosing the country of origin.

\subsection{Identification}

Our main parameter of interest is the coefficient on electricity prices. To give a sense of the range of the electricity prices, consider end-user electricity prices in 2011. Russia has some of the lowest prices at 4 US cents/kWh, while Japan is among the highest at $18 \mathrm{US}$ cents $/ \mathrm{kWh}$; most countries are within 8 and 16 US cents/kWh. For identification of the parameter on electricity prices in our model, however, we rely on variation over time in the electricity prices. Figure 2 shows the time series of electricity prices for a small subset of countries, and gives an indication of the variation which we rely on for identification.

We assume that these price variations are exogenous, and thus uncorrelated with other factors that might influence a firm's relocation decision. A threat to identification would be time-varying unobserved variables that are correlated with energy prices, as this would bias our estimate for the parameter on the price of electricity. While there is no way we can test directly for this correlation with time-varying unobservables, we can check if the electricity prices in our data are correlated over time with any of the observed time-varying variables. For most countries, the correlations between electricity prices and other variables that might affect a firm's relocation such as tax rates, EU membership, and export variables are weak (less than 0.6 in absolute value), giving some evidence in support of our identification

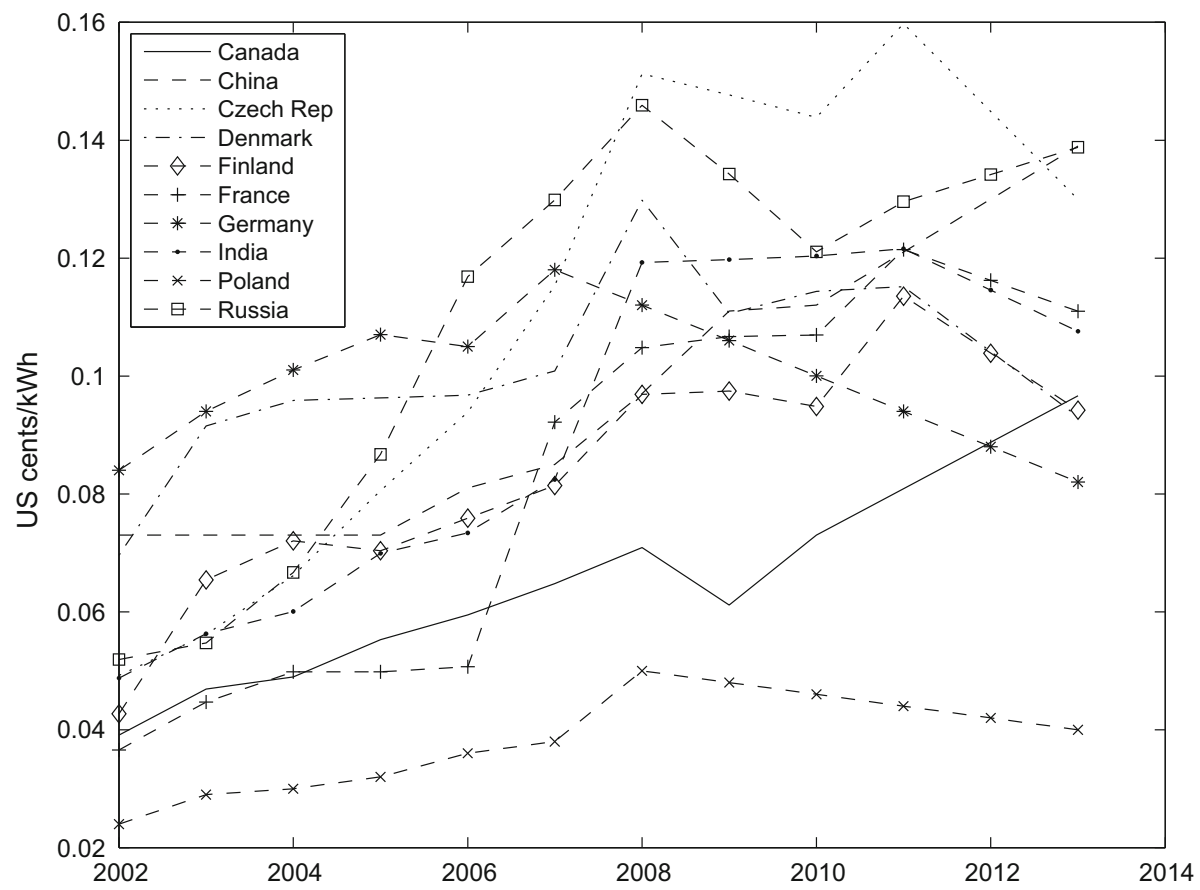

Fig. 2 Time series of end-user electricity prices for industry 
assumptions. The variable that is most highly correlated with electricity price is GDP, with the average country having a correlation coefficient for GDP and electricity prices of 0.74 over the sample period. Our assumption is that after controlling for GDP, per capita GDP, and trade variables, there is no other unobserved variable that varies over time in a similar way to electricity prices and influences firms' relocation calculations.

One major limitation of our study is that we use only prices for end-user electricity, which alone involved a great deal of difficulty in constructing the panel of data for our period of study, and must exclude other fuel types. Potential biases from excluding other fuel types come through two main channels. First, even if end-user electricity prices are uncorrelated with other fuels such as natural gas and coal, these fuels may serve as substitutes in some industries. Thus, the burden of an increase in electricity prices may not fall entirely on increasing production costs, if part of this can be offset by switching fuel types. To the extent that this occurs, our estimates for the effect of changing electricity prices on location decisions are underestimates, as that price variation would be a dampened measure of the full effect of firms experiencing increased costs.

A second channel through which excluding other fuel types yields biased results could occur if the prices of different fuels were correlated. In this situation, the effect we attribute to increasing electricity prices may indeed be due to price increases of other fuel types, and we would have no way to distinguish those effects. Therefore, we may be over-stating the effect due to electricity alone. In this case, we would do better to interpret the estimates as indicative of the effects of movements in fuel prices more broadly on location decisions of manufacturing firms.

\subsection{Conditional Logit Model Results}

In this section we first present the parameter estimates from the conditional logit model set out above. We then use these estimates to investigate how changing end-user electricity prices for industry affect the relocation decisions of manufacturing firms in the EU. The results from the estimation are given in Table 3 for various model specifications. These estimates look reasonable. The negative coefficient for Distance implies that a greater distance to destination country reduces the probability of relocating to that country; the positive coefficients on $E U$ and Language suggest that this cost is slightly mitigated when moving to a country that is a member of the EU or that has a common official language with the firm's country of origin (eg moving from Netherlands to Flanders). The negative parameter on Price_Electricity shows that an increased price of electricity serves to discourage firms from relocating to a particular country.

These parameter estimates allow us to calculate elasticities for our parameter of interest, Price_Electricity. We denote by $\eta_{i j t}$ the individual elasticity of $P_{i j t}$ with respect to the price of electricity, which given our type I extreme value assumption for $\epsilon_{i j t}$, gives us the formula

$$
\eta_{i j t} \equiv \frac{d \log P_{i j t}}{d \log \text { Price elec }_{\text {en }}}=\beta_{\text {price Price_elec }} \text { } t\left(1-P_{i j t}\right)
$$

We aggregate these individual elasticities by taking a weighted average in order to arrive at a global elasticity, which is reported at the bottom of Table 3 as $\eta_{\text {price }}{ }^{5}$ The demand for relocating to any particular country in our sample appears to be less than unit elastic with respect to the price of electricity, but certainly greater than zero. That is to say, firms are sensitive to the price of electricity in a country when making a relocation decision, conditional

5 Specifically, we use the formula $\eta_{\text {price }}=\frac{\sum_{i j t} \eta_{i j t} P_{i j t}}{\sum_{i j t} P_{i j t}}$. 
Table 3 Conditional relocation parameter estimates: where to move?

\begin{tabular}{|c|c|c|c|c|}
\hline & Model 1 & Model 2 & Model 3 & Model 4 \\
\hline Distance (100 thous. km) & $\begin{array}{l}-60.7293 * * \\
(7.6569)\end{array}$ & $\begin{array}{l}-55.9407 * * \\
(7.8033)\end{array}$ & $\begin{array}{l}-56.0569^{* *} \\
(7.8249)\end{array}$ & $\begin{array}{l}-56.0679 \text { ** } \\
(7.8379)\end{array}$ \\
\hline EU membership & & $\begin{array}{l}0.1075 \\
(0.2666)\end{array}$ & $\begin{array}{l}0.1054 \\
(0.2668)\end{array}$ & $\begin{array}{l}0.1276 \\
(0.2710)\end{array}$ \\
\hline Electricity price (US cents $/ \mathrm{kWh}$ ) & $\begin{array}{l}-5.5532^{* *} \\
(2.3605)\end{array}$ & $\begin{array}{l}-6.0839^{* *} \\
(2.4718)\end{array}$ & $\begin{array}{l}-6.1455^{* *} \\
(2.4915)\end{array}$ & $\begin{array}{l}-5.8426^{* *} \\
(2.5837)\end{array}$ \\
\hline GDP & & & $\begin{array}{l}-0.0539 \\
(0.2782)\end{array}$ & $\begin{array}{l}2.2174 \\
(2.2895)\end{array}$ \\
\hline GDP per capita & & & & $\begin{array}{l}-2.4029 \\
(2.2737)\end{array}$ \\
\hline Language & & $\begin{array}{l}0.5373 * * \\
(0.1718)\end{array}$ & $\begin{array}{l}0.5374 * * \\
(0.1718)\end{array}$ & $\begin{array}{l}0.5367 * * \\
(0.1718)\end{array}$ \\
\hline Tax Rate & & & & $\begin{array}{l}1.3783 \\
(1.2344)\end{array}$ \\
\hline Trade & & & & $\begin{array}{l}-0.0683 \\
(0.455)\end{array}$ \\
\hline$\eta_{\text {price }}$ & $\begin{array}{l}0.5325 \\
(0.2264)\end{array}$ & $\begin{array}{l}0.5828 \\
(0.2368)\end{array}$ & $\begin{array}{l}0.5888 \\
(0.2387)\end{array}$ & $\begin{array}{l}0.5595 \\
(0.2474)\end{array}$ \\
\hline $\mathrm{N}$ & 634 & 634 & 634 & 634 \\
\hline
\end{tabular}

The labelling of Model 1, Model 2, Model 3 and Model 4 refers solely to which right-hand side variables are included in the estimation

Significance results are $p \leq .05$ is $* *$ and $.05<p \leq .1$ is $*$

on having decided to relocate. We also present this elasticity broken down by country for a subsample of countries in Column 1 of Table 4. There are a few countries that approximate an elasticity of 1, such as Austria and Japan with respective values of 0.84 and 0.85, indicating that a $1 \%$ point change in the price of electricity in those countries would have a nearly proportional $\%$ point effect on the share of countries relocating to those countries. China, Canada, and Poland are all around 0.5, indicating that the share of firms relocating to those countries is relatively less sensitive to energy prices. For inelastic cases such as Russia, with an elasticity of 0.21 , this is likely driven by the very low current and recent energy prices, and the United States with 0.35 suggests that other factors are more important for decisions to locate there. Column 2 of Table 4 shows the $\%$ decrease in the share of firms relocating to a country if that country were to increase its price of electricity by $\$ 0.01 / \mathrm{kWh}$. Most countries experience between a 5-6\% decrease in their share of relocating firms.

The vector $\left\{\delta_{j}\right\}_{j=1}^{J}$ is normalized to have mean zero. It is interesting to see how these mean profit parameters vary across regions of the world, as depicted in Fig. 3. China has the highest mean profit, and Asian countries on the whole are above average. Not all firms relocate to Asia, however, because of the high travel costs that are paid for moving over such a long distance. Thus, there is still a significant share of firms relocating to Western and Eastern Europe, because although the mean profits are lower than in Asia and the Americas, distance costs are also much lower. To illustrate the importance of the distance, we can conduct a hypothetical counterfactual based on our parameter estimates. For example, we 
Table 4 Demand elasticity with respect to electricity prices for a selection of modelled countries

The first column shows elasticity of demand with respect to price elasticity. The second column shows the \% decrease in share of firms choosing a country when that country increases its price of electricity by $\$ 0.01 \mathrm{kWh}$

\begin{tabular}{lll}
\hline & $\eta_{\text {price }}$ & $\%$ Decrease \\
\hline Austria & 0.8413 & $5.63 \%$ \\
Brazil & 0.7443 & 5.60 \\
Canada & 0.4000 & 5.66 \\
China & 0.4646 & 4.71 \\
Croatia & 0.5836 & 5.66 \\
Czech Republic & 0.5521 & 5.17 \\
Denmark & 0.5905 & 5.62 \\
France & 0.4649 & 5.51 \\
Germany & 0.5836 & 5.28 \\
India & 0.5521 & 5.48 \\
Japan & 0.8557 & 5.66 \\
Poland & 0.4640 & 4.93 \\
Russia & 0.2189 & 5.60 \\
United Kingdom & 0.5923 & 5.54 \\
United States & 0.3521 & 5.46
\end{tabular}

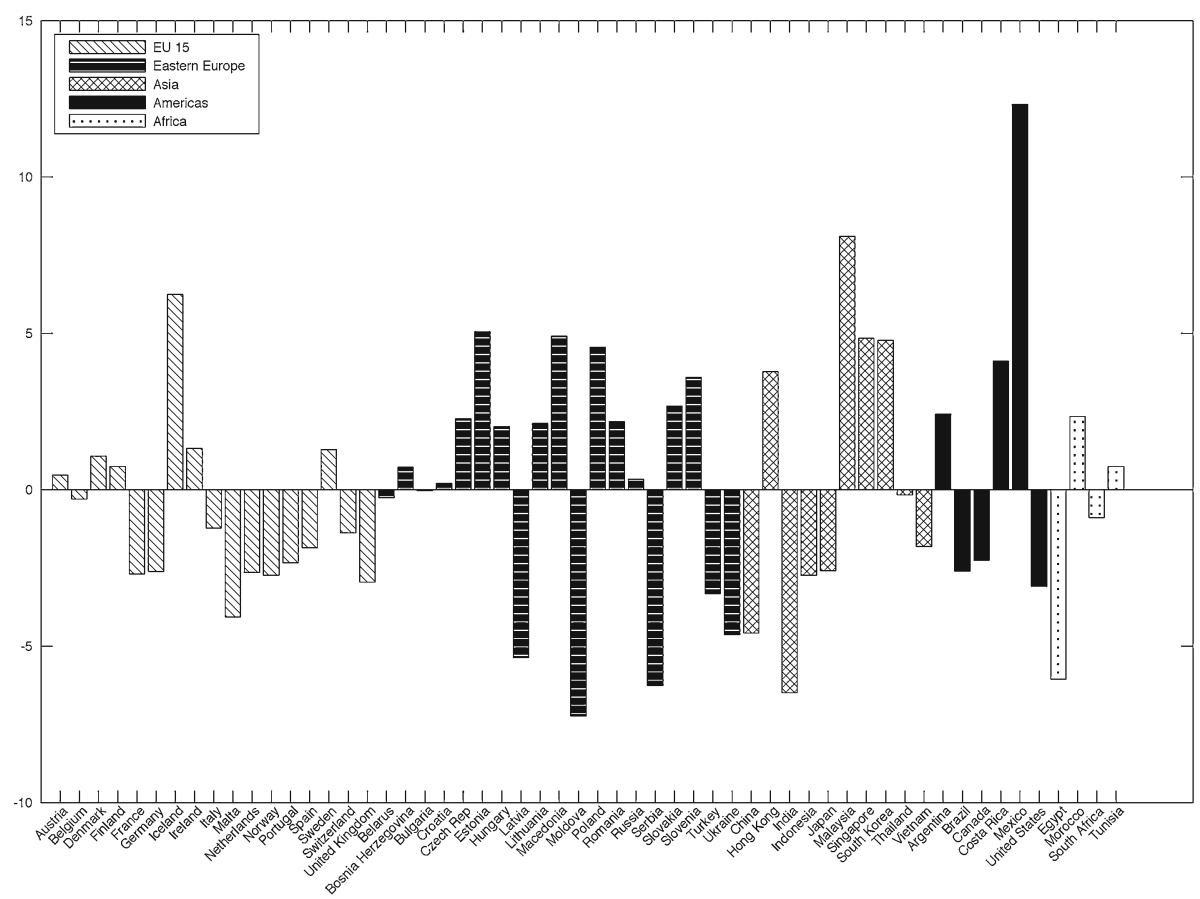

Fig. 3 Mean profit terms by region

can simulate the location decisions if China were located in Eastern Europe and thus had much lower moving costs associated with it. In our sample, we see $15 \%$ of firms that relocate go to China; under the counterfactual where China is "in" Eastern Europe, the share jumps to almost $85 \%$. 
Table 5 Conditional relocation parameter estimates: robustness to price interpolation

\begin{tabular}{|c|c|c|c|c|}
\hline & Model 1 & Model 2 & Model 3 & Model 4 \\
\hline Distance (100 thous. $\mathrm{km}$ ) & $\begin{array}{l}-53.245^{* *} \\
(8.417)\end{array}$ & $\begin{array}{l}-47.338 * * \\
(8.577)\end{array}$ & $\begin{array}{l}-47.987 * * \\
(8.605)\end{array}$ & $\begin{array}{l}-48.045^{* *} \\
(8.634)\end{array}$ \\
\hline EU membership & & $\begin{array}{l}-0.001 \\
(0.414)\end{array}$ & $\begin{array}{l}-0.0009 \\
(0.415)\end{array}$ & $\begin{array}{l}0.0342 \\
(0.425)\end{array}$ \\
\hline Electricity price (US cents/kWh) & $\begin{array}{l}-5.486^{*} \\
(3.106)\end{array}$ & $\begin{array}{l}-6.065^{*} \\
(3.131)\end{array}$ & $\begin{array}{l}-6.266^{*} \\
(3.141)\end{array}$ & $\begin{array}{l}-5.907 * \\
(3.324)\end{array}$ \\
\hline GDP & & & $\begin{array}{l}-0.231 \\
(0.303)\end{array}$ & $\begin{array}{l}2.343 \\
(2.926)\end{array}$ \\
\hline GDP per capita & & & & $\begin{array}{l}-2.720 \\
(2.883)\end{array}$ \\
\hline Language & & $\begin{array}{l}0.716 * * \\
(0.183)\end{array}$ & $\begin{array}{l}0.715^{* *} \\
(0.183)\end{array}$ & $\begin{array}{l}0.722 * * \\
(0.184)\end{array}$ \\
\hline Tax Rate & & & & $\begin{array}{l}-2.193 \\
(1.596)\end{array}$ \\
\hline Trade & & & & $\begin{array}{l}-0.235 \\
(0.515)\end{array}$ \\
\hline$\eta_{\text {price }}$ & $\begin{array}{l}0.540 \\
(0.226)\end{array}$ & $\begin{array}{l}0.600 \\
(0.237)\end{array}$ & $\begin{array}{l}0.602 \\
(0.239)\end{array}$ & $\begin{array}{l}0.588 \\
(0.247)\end{array}$ \\
\hline $\mathrm{N}$ & 537 & 537 & 537 & 537 \\
\hline
\end{tabular}

The labelling of Model 1, Model 2, Model 3 and Model 4 refers solely to which right-hand side variables are included in the estimation. This table exactly replicates the main estimation from Table 3, but drops all countries for which the electricity price had to be interpolated. At the cost of some statistical power and precision, this robustness test shows similar effects as before

Significance results are $p \leq .05$ is $* *$ and $.05<p \leq .1$ is $*$

We investigated alternative specifications to test for robustness of these results. Since firms might have made the decision to relocate in advance of the announcement date that is recorded in our data, we estimated the model using lagged electricity price. When prices are lagged by one year, the parameter estimates are nearly identical and still significant, and the elasticities are of the same magnitude. With electricity prices are lagged by two years, the parameter estimates become smaller and are only significant at the $90 \%$ level. We also attempted to model the effect of the firm responding to the relative price between the destination country and the country of origin by weighting the electricity prices by the price in the home country. In this specification, however, the coefficient on price of electricity was smaller and no longer statistically significant. As an additional robustness check, because of limited price data for some locations, we repeat the analysis using only those countries for which a complete price data is available. These results, shown in Table 5, show similar results to the main analysis, albeit at the cost of some precision in estimates due to smaller sample size.

\section{Nested Logit Relocation Model: The Decision to Move and Where to Move}

The previous section modeled firm location choice conditional on having already decided to relocate. However, for a policy maker the more interesting question is to what degree climate 
change policies affect a firm's decision to relocate or not, as well as the choice of destination for firms that do decide to move their production activity. In this section, we approximate the total number of manufacturing firms in the EU in order to expand our model to include the participation decision. This allows for a more complete picture of plant relocation and is useful for giving a more meaningful examination of the effects of climate change policies which drive up energy costs.

To do this, we approximate the share of firms that relocate by using an estimate of the total number of medium and large manufacturing firms in the EU. We obtained from Eurostat estimates of the number of manufacturing firm with 250+ employees for each country in the EU, since the ERM data only captures relocations of medium to large firms that involve significant job loss. The Eurostat data on firm size distribution for 2012 is the most complete, and so we use those numbers which suggest a total of 15,833 manufacturing firms across the EU with 250+ employees, and we have also the distribution of the location of these firms across EU countries. These numbers suggest a very small share of firms relocate. In our empirical application, we assume that each year over our 12 year sample period, $10 \%$ of the large firms in each country are faced with the decision of whether to relocate or not, and if they decide to relocate, to where to relocate. This is to ease the computational burden of estimation, and also to incorporate that large firms are not considering relocation at every moment. This means that our preferred specification will have $\mathrm{N}=1500$ decision makers in each year, and for robustness, we report estimates for various sizes of this share.

With data on the total numbers of firms (and thus also the share that relocate), we can extend the model where firms have two stages of decision making. First, firms decide whether to move or not. After deciding to move, a firm then decides which destination country to move to. The current setup will be a static framework, so firms are not making decisions taking into account expectations of future states. Rather, here firms are modeled as exogenously having the opportunity to move at each time period $t$, where if a firm decides to relocate from country i to country $\mathrm{j}$ it receives:

$$
\pi_{i j t}=\delta_{j}+\beta_{1} \text { Price_elec }_{j t}+\beta_{2} G D P_{j t}+\beta_{3} \text { Trade }_{i j t}+\theta^{\prime} M C_{i j}+\epsilon_{i j t}
$$

with a moving cost

$$
\theta^{\prime} M C_{i j}=\theta_{1} \text { Dist }_{i j}+\theta_{2} \text { Lang }_{i j}+\theta_{3} E U_{j t}
$$

While if a firm decides to stay, it receives the mean utility (profits) for its country of origin, $\delta_{\text {origin }}$ and does not pay the moving cost, so it receives:

$$
\pi_{i 0 t}=\delta_{\text {origin }}+\beta_{1} \text { Price_elec } c_{\text {origin }, t}+\beta_{2} G D P_{\text {origin }, t}+\epsilon_{i j t}
$$

We model the firm decision as first deciding whether to relocate or not, and then only after a decision to relocate, the firm chooses a country of destination. This model requires that we impose a nesting structure, so that the country of origin is in one (degenerate) nest, and all the other countries are in another nest. The error term $\epsilon_{i j t}$ is assumed to be distributed type 1 extreme value, but rather than being independent across all choice, there is now correlation among alternatives in the same nest; this allows us to still calculate the choice probabilities, $P_{i j t}$ in a closed form. ${ }^{6}$ Estimation of the parameters follows using essentially the same method as before, with the additional estimation of the moving cost constant $\theta_{1}$ and a nesting parameter, $\lambda_{\text {move }}$. This provides a more complete picture in any counterfactual scenarios one might want to examine by approximating the stickiness firms face in deciding whether to move.

6 The choice probabilities in the nested logit require another parameter that measures the importance of the nest, which we denote $\lambda_{k}$ for nest $B_{k}$. If we denote the profit $\pi_{i j t}=V_{i j t}+\epsilon_{i j t}$, the choice probabilities for 


\subsection{Results for the Nested logit}

The results for the nested logit relocation model are analogous to those of the previous section, with the addition that as we now model the decision to relocate or stay, we can estimate a moving cost constant, $\theta_{1}$, which is incurred only when a firm decides to relocate, and a nesting parameter $\lambda_{\text {move }}$. We also calculate elasticities separately for domestic and foreign firms. We use a similar formula to calculate individual elasticities $\eta_{i j t}$ as before, ${ }^{7}$ and denote by $I_{j}$ (resp. $I_{j}^{c}$ ) the set of all firms originating in country $\mathrm{j}$ (resp. outside of country $\mathrm{j}$ ). Then we can define the country j level elasticities $\eta_{\text {domestic }}^{j}$ and $\eta_{\text {foreign }}^{j}$ as:

$$
\begin{gathered}
\eta_{\text {domestic }}^{j}=\frac{d \log \left(\sum_{i \in I_{j}} P_{i j t}\right)}{d \log \text { Price_elec }}=\frac{\sum_{i \in I_{j}} P_{i j t} \eta_{i j t}}{\sum_{i \in I_{j}} P_{i j t}} \\
\eta_{\text {foreign }}^{j}=\frac{d \log \left(\sum_{i \in I_{j}^{c}} P_{i j t}\right)}{d \log \text { Price_elec }}=\frac{\sum_{i \in I_{j}^{c}} P_{i j t} \eta_{i j t}}{\sum_{i \in I_{j}^{c}} P_{i j t}}
\end{gathered}
$$

By taking a weighted sum of each $\eta_{\text {domestic }}^{j}$ across all the countries $\mathrm{j}$, we arrive at an aggregate elasticity:

$$
\eta_{\text {domestic }}=\frac{\sum_{i \in I_{1}} P_{i 1 t} \eta_{i 1 t}+\sum_{i \in I_{2}} P_{i 2 t} \eta_{i 2 t}+\ldots+\sum_{i \in I_{J}} P_{i J t} \eta_{i J t}}{\sum_{i \in I_{1}} P_{i 1 t}+\sum_{i \in I_{2}} P_{i 2 t}+\ldots+\sum_{i \in I_{J}} P_{i J t}}
$$

and use an analogous definition for $\eta_{\text {foreign }}$.

These results are reported in Table 6 and shown in Fig. $4 .{ }^{8}$ The elasticity for domestic firms $\eta_{\text {domestic }}$ is very low, indicating that domestic firms are rather un-responsive to increases in their domestic energy prices when deciding whether or not to relocate. This is due to having such a large share of firms in each domestic country that do not relocate in a multinomial logit specification. On the other side, this model allows us to also study the responsiveness of foreign firms to domestic energy prices, to give a sense of how much a country might be able to attract foreign firms by having lower energy prices. This responsiveness is indicated by $\eta_{\text {foreign }}$, which corresponds to the results from the Conditional Relocation Model from the previous section. Our estimates range from 0.58 to 0.76 , suggesting there is a higher

Footnote 6 continued

choosing an alternative $i$ which is in nest $B_{k}$ then take the form $P_{i j t}=\frac{e^{\frac{V_{i j t}}{\lambda_{k}}}\left(\sum_{j \in B_{k}} e^{\frac{V_{i j t}}{\lambda_{k}}}\right)^{\lambda_{k}-1}}{\sum_{l=1}^{K}\left(\sum_{j \in B_{l}} e^{\frac{V_{i j t}}{\lambda_{l}}}\right)^{\lambda_{l}} \text {. Note that }}$ if the estimated nesting parameter $\lambda_{k}$ is one, the choice probabilities and the model reduce to the standard logit that we used before. As the nesting parameter goes to zero, this indicates the importance in the nesting of alternatives, and signals that the more flexible nested logit captures a more realistic substitution pattern.

7 Elasticities in the nested logit are given by $\left[\left(1-P_{i j t}\right)+\left(\frac{1-\lambda_{\text {move }}}{\lambda_{\text {move }}}\right)\left(1-P_{i j t \mid B_{k}}\right)\right] \beta_{\text {price }}$ Price_elec $j$. Note again that with $\lambda_{\text {move }}$ equal to 1 , the elasticities would be exactly the same as the standard logit case used before.

8 We also estimated the unconditional relocation model without the nesting structure. Because the nesting parameter $\lambda_{\text {move }}$ is different than 1, suggesting a standard logit is mis-specified, we present only the nested model logit. Elasticities were very similar under both models, the main difference was that the nested logit estimated smaller moving costs, while the i.i.d. structure of the error term in the standard logit drove the moving cost estimate to be larger in magnitude. 


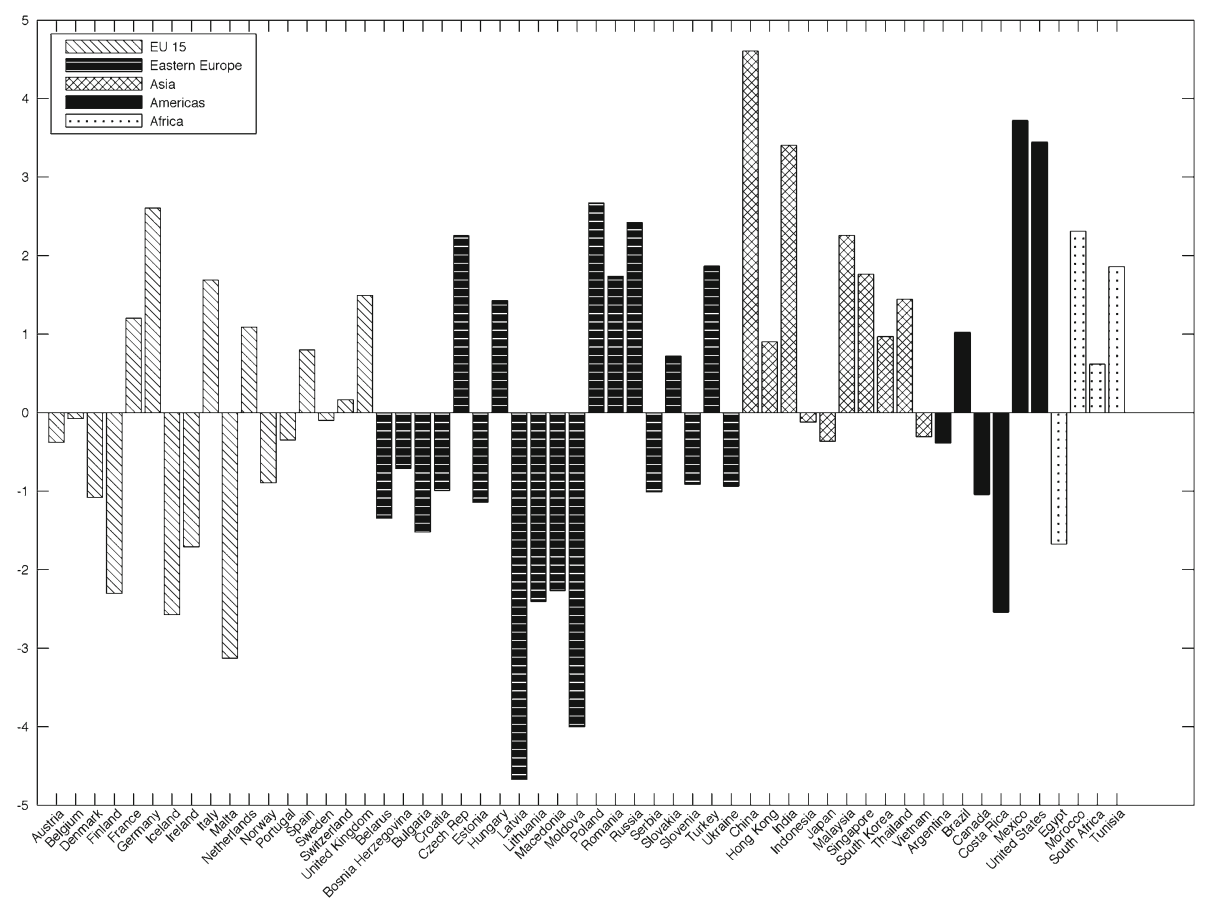

Fig. 4 Mean profit terms from nested logit

responsiveness to variations in energy costs in terms of attracting foreign firms that have already decided to move.

Table 7 includes robustness checks on what is assumed regarding the outside share. With $\mathrm{N}$ firms making a location decision each period, $\mathrm{N}=800,1000$, and 1500 correspond to an outside share of $.93, .94$, and .96 respectively. Although the point estimates do vary, the elasticities remain with a reasonable range, with for example the elasticity on foreign firms remaining high but below unity (from 0.71 to 0.89 ).

\section{Firm Heterogeneity}

It seems likely that, at the margin, there are some firms are more responsive to the cost burdens imposed by environmental regulations. For example, some heavily polluting manufacturing plants may be more likely to relocate in response to new regulations, and such firms may face a tradeoff between upgrading to cleaner technology or relocating, and large differences in national regulatory environments can have a big influence on these decisions. Moreover, heterogeneity among industries in levels of pollution and moving costs may result in a heterogeneous response to increases in energy costs across specific industries. Similarly, one can speculate that firms which operate in more energy-intensive sectors are more likely to respond to increases in energy costs than those in less energy-intensive sectors. While our data are not particularly well-suited to investigate firm heterogeneity in great detail, we can make use of 2 digit sector codes to create a set of high energy intensive industries and a set 
Table 6 Nested logit models: whether to move and where to move

\begin{tabular}{|c|c|c|c|c|}
\hline & Model 1 & Model 2 & Model 3 & Model 4 \\
\hline Distance (100 thous. km) & $\begin{array}{l}-5.8897^{* *} \\
(1.8525)\end{array}$ & $\begin{array}{l}-8.3682^{* *} \\
(1.9558)\end{array}$ & $\begin{array}{l}-8.4451^{* *} \\
(1.9696)\end{array}$ & $\begin{array}{l}-8.7546^{* *} \\
(2.0133)\end{array}$ \\
\hline EU membership & & $\begin{array}{l}0.147 * * \\
(0.066)\end{array}$ & $\begin{array}{l}0.1475 * * \\
(0.0662)\end{array}$ & $\begin{array}{l}0.1644 * * \\
(0.0704)\end{array}$ \\
\hline Electricity price (US cents/kWh) & $\begin{array}{l}-0.5782^{* *} \\
(0.2858)\end{array}$ & $\begin{array}{l}-1.3273^{* *} \\
(0.4713)\end{array}$ & $\begin{array}{l}-1.3623^{* *} \\
(0.482)\end{array}$ & $\begin{array}{l}-1.29995^{* *} \\
(0.4818)\end{array}$ \\
\hline GDP & & & $\begin{array}{l}-0.02 \\
(0.0423)\end{array}$ & $\begin{array}{l}0.3315 \\
(0.3383)\end{array}$ \\
\hline GDP per cap & & & & $\begin{array}{l}-0.3294 \\
(.3352)\end{array}$ \\
\hline Language & & $\begin{array}{l}0.0903 * * \\
(0.0309)\end{array}$ & $\begin{array}{l}0.0907 * * \\
(0.031)\end{array}$ & $\begin{array}{l}0.0932 * * \\
(0.0316)\end{array}$ \\
\hline Tax rate & & & & $\begin{array}{l}-0.1084 \\
(0.1974)\end{array}$ \\
\hline Trade & & & & $\begin{array}{l}-0.0802 \\
(0.0749)\end{array}$ \\
\hline$\eta_{\text {domestic }}$ & 0.0023 & 0.0052 & 0.0054 & 0.0051 \\
\hline$\eta_{\text {foreign }}$ & 0.5945 & 0.8735 & 0.8918 & 0.8247 \\
\hline$\lambda_{\text {move }}$ & 0.0984 & 0.1541 & 0.1549 & 0.1596 \\
\hline Moving costs & -3.6329 & -3.9758 & -3.9786 & -4.0099 \\
\hline $\mathrm{N}$ & 1500 & 1500 & 1500 & 1500 \\
\hline
\end{tabular}

The labelling of Model 1, Model 2, Model 3 and Model 4 refers solely to which right-hand side variables are included in the estimation

Significance results are $p \leq .05$ is $* *$ and $.05<p \leq .1$ is $*$

of low energy intensive industries. ${ }^{9}$ That is, we use energy intensity information to partition our data set.

We account for sectoral heterogeneity in energy intensity by adding an interaction of the electricity price with an indicator for being in an energy intensive sector. The profit function from the previous sections then takes the form:

$\pi_{i j t}=\delta_{j}+\left(\beta_{1}+\gamma \times\right.$ INTENSE $\left._{i}\right)$ Price_elec $j t+\beta_{2} G D P_{j t}+\beta_{3}$ Trade $_{i j t}+\theta^{\prime} M C_{i j}+\epsilon_{i j t}$

where INTENSE $E_{i}$ is an indicator for firm i belonging to an energy intensive sector, so that we now estimate an extra parameter $\gamma$ which reflects the importance of the electricity price for firms in energy intensive sectors, beyond the effect for firms that are not in energy intensive sectors.

9 This categorization is derived based on the DECC (2012) Annual Industrial Energy Consumption Tables for the UK. This source has total annual electricity consumption information per sector expressed in ' 000 $\mathrm{MWh} /$ year, which was divided by the number of enterprises in the sector in the UK as reported in Eurostat. This is a crude statistic as electricity consumption varies considerably within the two digit level sector classification used here; therefore we create two groupings, one includes energy intensive industries and another-the remainder of sectors. Energy intensive industries include pharmaceuticals, paper, electronics, chemicals, basic metals, tobacco products and coke and refined petroleum products. 
Table 7 Nested logit model: robustness check using differing values of $\mathrm{N}$

\begin{tabular}{llll}
\hline & Model 1 & Model 2 & Model 3 \\
\hline Distance (100 thous. km) & $-4.9569 * *$ & $-6.0603 * *$ & $-12.8038^{* *}$ \\
EU membership & $(2.1794)$ & $(2.0701)$ & $(2.3983)$ \\
& 0.0306 & 0.0615 & $0.2662^{* *}$ \\
Electricity price (US cents/kWh) & $(0.0316)$ & $(0.0448)$ & $(0.0857)$ \\
& $-0.6279 * *$ & $-0.8237 * *$ & $(0.5769)$ \\
GDP & $(0.3621)$ & $(0.392)$ & -0.0428 \\
& -0.0095 & -0.0126 & $(0.0605)$ \\
Language & $(0.0251)$ & $(0.0302)$ & $0.1409 * *$ \\
& $0.0487^{*}$ & $0.0624 * *$ & $(0.0416)$ \\
$\eta_{\text {domestic }}$ & $(0.0252)$ & $(0.027)$ & 0.0082 \\
$\eta_{\text {foreign }}$ & 0.0048 & 0.0051 & 0.8964 \\
$\eta_{\text {move }}$ & 0.7171 & 0.7718 & 0.2247 \\
Moving costs & 0.0886 & 0.1081 & -4.3116 \\
N & -2.9831 & -3.3153 & 1500 \\
\hline
\end{tabular}

The labelling of Model 1, Model 2 and Model 3 refers to the assumed size of $\mathrm{N}$

Significance results are $p \leq .05$ is $* *$ and $.05<p \leq .1$ is $*$

The results are presented in Table 8 . With only 166 firms in energy intensive sectors, we are not able to find statistically significant estimates for the interaction effect. The point estimate is, however, large and in the expected direction, indicating that energy intensive sectors are more responsive to energy prices. Indeed this is reflected in the corresponding elasticities, where low energy intensive firms have an elasticity around 0.4, while the energy intensive sectors firms have an elasticity of 0.8. A larger dataset or one with more detailed firm characteristics such as sector beyond the two digit NACE code would be required to investigate this question more precisely.

\section{Conclusions}

The Pollution Havens Hypothesis suggests that increasingly-strict environmental policies act as a dis-incentive to firms to locate in a given country. If this effect is significant, then increasingly-strict climate change policies in Europe would simply result in the displacement of polluting emissions to areas of the world with less-severe environmental regulation. One way of thinking about these effects is through the costs of inputs to production. In this study we are able to statistically measure a relationship between a proxy for energy costs-end-user electricity prices-and location choice for manufacturing plants which have the possibility of moving into, or out of, or within, European Union countries.

The magnitude of the effects that we find of electricity prices on firm's re-location decisions are significant, although the elasticity of location choice with respect to electricity prices is always less than or equal to one. We also find an interesting asymmetry in the effects of rising electricity prices. A country can try to attract a relocating foreign firm by lowering production costs through having less strict environmental policies, and this will affect the responsiveness 
Table 8 Check for firm heterogeneity, conditional model

\begin{tabular}{lllll}
\hline & Model 1 & Model 2 & Model 3 & Model 4 \\
\hline Distance (100 thous. km) & $-60.5193^{* *}$ & $-55.7853^{* *}$ & $-55.8921^{* * *}$ & $-55.9389^{* *}$ \\
& $(7.6614)$ & $(7.8085)$ & $(7.8299)$ & $(7.8432)$ \\
EU membership & & 0.1063 & 0.1043 & 0.1074 \\
& & $(0.2667)$ & $(0.2669)$ & $(0.2685)$ \\
Electricity price high intensity & -4.0046 & -3.8089 & -3.8006 & -3.7978 \\
& $(2.7081)$ & $(2.7057)$ & $(2.7034)$ & $(2.7034)$ \\
Electricity price (US cents/kWh) & $-4.4872^{* *}$ & $-5.0604^{* *}$ & $-5.1191^{* *}$ & $-5.0723^{* *}$ \\
& $(2.4536)$ & $(2.5647)$ & $(2.5851)$ & $(2.6265)$ \\
GDP & & & -0.0498 & -0.0292 \\
& & & $(0.2784)$ & $(0.3464)$ \\
Language & & $0.533^{* *}$ & $0.5328^{* *}$ & $0.5323^{* *}$ \\
& & $(0.1719)$ & $(0.1719)$ & $(0.172)$ \\
Trade & & & & -0.0456 \\
& & & & $(0.4546)$ \\
$\eta_{\text {price }}^{\text {hign }}$ & & 0.8143 & 0.819 & 0.8145 \\
$\eta_{\text {price }}^{\text {low }}$ & 0.7796 & 0.4921 & 0.4979 & 0.4934 \\
$\mathrm{~N}$ & 0.4371 & 634 & 634 & 634 \\
\hline
\end{tabular}

The labelling of Model 1, Model 2, Model 3 and Model 4 refers solely to which right-hand side variables are included in the estimation

Significance results are $p \leq .05$ is ** and $.05<p \leq .1$ is *

of a foreign firm with an estimated mean elasticity of $\eta_{\text {foreign }} \approx 0.7$. On the other hand, a country might fear that imposing environmental regulation will cause domestic firms to leave. However, we found a very low responsiveness of domestic firms to increasing energy costs, with an elasticity of $\eta_{\text {domestic }} \approx .005$. This marked asymmetry is partly a consequence of the multinomial logit specification and the resulting expression for elasticities: since most domestic firms remain at home, $P_{i j t}$ is high for domestic firms, and therefore the elasticity $\beta_{\text {price Price_elec }}\left(1-P_{i j t}\right)$ will be small, while the opposite occurs for the foreign firms. But the asymmetry is also consistent with our assumed firm decision process. In the short to medium term, if most domestic firms are not considering relocation, it would take a large change in input prices in order for them to even consider incurring the fixed costs of a re-location. In the long term, for capital intensive industry, once the asset lifetime expires, relocation fixed costs would be lower and the chance of relocation would be marginally higher. By contrast, from the perspective of home country $i$, there are many foreign firms (the domestic firms in all other countries), and if even a small number are considering relocation from each country, in sum this group of relocating firms may be sizeable. Having decided it is worthwhile to incur the fixed moving costs, they may be more sensitive to small changes in energy prices in potential destination country $j$ in choosing where to relocate.

We also found that the responsiveness of firms to higher energy costs in terms of the probability of them re-locating was about twice as large for high energy users than for low energy users. This suggests one reason why governments might want to find means of reducing the financial burden of climate policies on high-energy use sectors.

We are not able to determine whether countries are setting environmental standards below socially efficient levels in order to attract and maintain firms, as this would require some 
measure of the social cost of pollution. Particularly in the case of climate change, these costs are hard to estimate. But our results indicate that countries should not expect many domestic firms to leave in the short term as a result of regulations that lead to increases in the costs of production for manufacturing firms. It may, however, be modestly more difficult to attract foreign firms when domestic climate policy is strengthened in a way which increases end-user energy prices. If this is a significant concern of policy-makers, then this would place more importance on a coordinated regulatory frameworks across countries.

Finally, it is important to note that the effects of variations in electricity prices were explicitly modelled here, not the effects of price changes for all energy inputs which firms make use of. This would clearly be a potentially interesting extension to the paper. Since a carbon tax would also affect the prices of fuels which can substitute for electricity as inputs to production, our results do not show the full effects on carbon leakage or on firm location decisions of such a tax. Moreover, we do not model the link between environmental policy-setting and electricity prices, which is important since, as noted, many factors jointly determine these energy prices. The dynamics of the problem are also not studied in this paper, apart from an investigation of the effects of using lagged prices. Given the typical investment cycles of particularly high-energy intensity industries, then over the longer term (say $>20$ years), we might see much bigger effects on relocation decisions of sustained differences in wholesale energy prices. However, the data set does not enable us to test for such long-run dynamics. Finally, one might anticipate that firm size would co-determine the probability that a firm would choose to re-locate in response to higher energy costs. Again, this is not investigated in the present paper.

Acknowledgements We thank the referees and co-editor Anthony Heyes for some very helpful comments. We also thank Chris Timmins for suggestions regarding the modelling approach.

Open Access This article is distributed under the terms of the Creative Commons Attribution 4.0 International License (http://creativecommons.org/licenses/by/4.0/), which permits unrestricted use, distribution, and reproduction in any medium, provided you give appropriate credit to the original author(s) and the source, provide a link to the Creative Commons license, and indicate if changes were made.

\section{References}

Baumol W, Oates W (1988) The theory of environmental policy. Cambridge University Press, New York

Bayer P, Murphy A, McMillan R, Timmins C. (2011) A dynamic model of demand for houses and neighborhoods. NBER working paper no. 17250

Ben Kheder S, Zugravu N (2008) The pollution haven hypothesis: a geographic economy model in a comparative study. FEEM working paper no. 73

Ben-Akiva M, Lerman S (1985) Discrete choice analysis. MIT Press, Cambridge

Bresnahan TF, Reiss PC (1991) Entry and competition in concentrated markets. J Polit Econ 99(5):977-1009

Broeren MLM, Saygin D, Patel MK (2014) Forecasting global developments in the basic chemical industry for environmental policy analysis. Energy Policy 64:273-287

Brunnermeier SB, Levinson A (2004) Examining the evidence on environmental regulations and industry location. J Environ Dev 13(1):6-41

Buch C, Kleinert J, Lipponer A, Toubal F (2005) Determinants and effects of foreign direct investment: evidence from German firm-level data. Econ Policy 41:51-110

Cole M, Elliott RJR (2005) FDI and the capital intensity of "dirty" sectors: a missing piece of the pollution haven puzzle. Rev Dev Econ 9(4):530-548

Conrad K (2005) Locational competition under environmental regulation when input prices and productivity differ. Ann Reg Sci 39(2):273-295

Copeland B, Taylor MS (2004) Trade, growth and the environment. J Econ Lit 42(1):7-71

Commins N, Lyons S, Schiffbauer M, Tol NC (2011) Climate policy and corporate behavior. Energy J 32(4) 
DECC (2012) Energy consumption in the UK. Industrial data tables. 2012 Update. http://www.decc.gov.uk/ en/content/cms/statistics/publications/ecuk/ecuk.aspx

Elliot J, Fullerton D (2014) Can a unilateral carbon tax reduce emissions elsewhere? Resour Energy Econ 36(91):6-21

Eskeland GS, Harrison AE (2003) Moving to greener pastures? Multinationals and the pollution haven hypothesis. J Dev Econ 70(1):1-23

Fischer C, Fox AK (2012) Climate policy and fiscal constraints: do tax interests outweigh carbon leakage? Energy Econ 34(2):S218-S227

Frontier Economics and EWI (2010) Energiekosten in Deutschland-Entwicklungen, Ursachen und internationaler Vergleich (Projekt 43/09) http://www.bmwi.de/

Head K, Mayer T (2004) Market potential and the location of Japanese investment in the European Union. Rev Econ Stat 86(4):959-972

ICF (2012) An international comparison of energy and climate change policies impacting energy intensive industries in selected countries. Report for the Department for Business Innovation and Skills. http://www.bis.gov.uk/assets/biscore/business-sectors/docs/i/12-527-international-policiesimpacting-energy-intensive-industries.pdf

Jeppesen T, List JA, Folmer H (2002) Environmental regulations and new plant location decisions: evidence from a meta-analysis. J Reg Sci 42(1):19-49

Lavric L (2013) Relocation of industry from the EU, links to electricity charges and implications for environmental policy making. Dissertation for MSc in Economics, University of Edinburgh. http://www. encompassadvisory.co.uk/\#!notes/c24vq

Levinson A (1996) Environmental regulations and manufacturers' location choices: evidence from the census of manufacturers. J Public Econ 62(1-2):5-29

List JA, Mason CF (2001) Optimal institutional arrangements for transboundary pollutants in a second-best world: evidence from a differential game with asymmetric players. J Environ Econ Manag 42:277-296

Manderson E, Kneller R (2012) Environmental regulations, outward FDI and heterogeneous firms: are countries used as pollution havens? Environ Resour Econ 51(3):317-352

Martin R, Muuls M, de Preux L, Wagner U (2014) Industry compensation under relocation risk: a firm-level analysis of the EU emissions trading scheme. Am Econ Rev 104(8):2482-2508

McFadden DL (1974) Conditional logit analysis of qualitative choice behavior. In: Zarembka P (ed) Frontiers in econometrics. Academic Press, New York, pp 105-142

Millimet DL, List J (2004) The case of the missing pollution haven hypothesis. J Regul Econ 26(3):239-262

Öko-InstituteV, Ecofys (2013) Support to the Commission for the determination of the list of sectors and subsectors deemed to be exposed to a significant risk of carbon leakage for the years 2015-2019. http:// ec.europa.eu/clima/policies/ets/cap/leakage/studies_en.htm

Pearson CS (1987) Multinational corporations, environment, and the third world. Duke University Press, Durham

Ratti RA, Seol Y, Yoon K (2011) Relative energy price and investment by European firms. Energy Econ 33(2011):721-731

Rauscher M (1994) On ecological dumping. Oxf Econ Pap 46:822-840

Rauscher M (1997) International trade, factor movements and the environment. Oxford University Press, Oxford

Rauscher M (2000) Hot spots, high smokestacks, and the geography of pollution. Paper presented at a conference held on the occasion of the 150th anniversary of Johann-Heinrich von Thünen's death. Mimeo, Rostock

Smarzynska BK, Wei S-J (2001) Pollution havens and foreign direct investment: dirty secret or popular myth? World Bank working paper. World Bank, Washington, DC

Ulph A (1997) International trade and the environment. In: Folmer H, Tietenberg T (eds) The international yearbook of environmental and resource economics 1997-98. Survey of current issues. Edward Elgar, Cheltenham, pp 205-242

Ulph A (2000) Environment and trade. In: Folmer H, Gabel HL (eds) Principles of environmental and resource economics. Edward Elgar, Cheltenham

Verbeke T, de Clerq M (2002) Environmental quality and economic growth. Gent University working paper

Wagner UJ, Timmins CD (2009) Agglomeration effects in foreign direct investment and the pollution haven hypothesis. Environ Resour Econ 43:231-256

Wilson JD (1996) Capital mobility and environmental standards: is there a theoretical basis for a race to the bottom. In: Bhagwati J, Hudec RP (eds) Fair trade and harmonization: prerequisites for free trade, vol 1. MIT Press, Cambridge, pp 393-427 